\title{
MULTIPLE STANDARDIZATION OF PARASUICIDE ('ATTEMPTED SUICIDE') RATES IN EDINBURGH
}

\author{
DOROTHY BUGLASS, B.A., M.Phil., P. DUGARD, M.A. AND NORMAN KREITMAN, M.D., D.P.M. \\ M.R.C. Unit for Epidemiological Studies in Psychiatry, Edinburgh University Department of Psychiatry, \\ Royal Edinburgh Hospital, Morningside Park, Edinburgh, EH 10 5HF
}

Several studies of 'attempted suicide', better termed parasuicide, have been carried out in Edinburgh in recent years. The city is well placed for such studies as the great majority of cases receiving hospital attention are admitted to the Regional Poisoning Treatment Centre (RPTC) at the Royal Infirmary. Statistics compiled by the Scottish Home and Health Department show that in $196795 \%$ of all adult patients admitted to hospital from an Edinburgh address for treatment of poisoning were received by the RPTC. Cases of self-injury are also received at the RPTC though they are less systematically referred than are the poisoning cases and thus likely to be less fully represented than the former. However, if we assume, as is likely to be the case, that only a small proportion of all parasuicides are self-injuries, it would be reasonable to consider RPTC admissions an approximation to the number of all hospitalized parasuicides in Edinburgh.

Previous studies have described the individual and ecological characteristics of parasuicides (e.g., Kessel, 1965; Philip and McCulloch, 1966). It is already established that different areas of the city have widely different rates for parasuicide. Moreover, high rate areas have retained their relative positions despite an overall increase in the city as a whole Aitken, Buglass and Kreitman, 1969). Areas where parasuicide is prevalent are also characterized by other indices of poor living conditions and deviant behaviour. In particular, high parasuicide rates are correlated with high rates for overcrowding, completed suicide and child neglect (Philip and McCulloch, 1966; McCulloch, Philip and Carstairs, 1967).

In this study we sought to determine whether the differences in parasuicide rates between areas could be explained as a reflection of other differences in certain social and demographic characteristics of the area populations. In other words, we posed the question: if the population in all areas (electoral wards) of the city had a similar distribution for each of several variables, would the attempted suicide rate then be the same in all areas? If the answer is affirmative, then the excess of parasuicides in certain areas is thereby 'explained'. If the answer is negative and area differences still persist when their populations are simultaneously standardized on several social variables, we have demonstrated that these areas must be distinguished by other, as yet unknown, factors to which further investigation may be directed.

\section{Choice of VARIABles}

The variables chosen for study were those which satisfied the following criteria:

1. They were known to be related to parasuicide.

2. They described an individual's position in society.

3. Information about them had to be availableo both for the parasuicide group and for the population of the city.

Earlier work in Edinburgh has shown that rates for parasuicide vary according to sex, age, marital status and overcrowding (Kessel, 1965; Aitken et al., 1969). Further analyses have also demonstrated high rates for the unemployed and for people in the lower social classes. Information on these six variables was collected in the $10 \%$ Sample Census (1966). These items were also recorded for parasuicides. A further item used by several investigators-single person households-was considered but rejected because persons living alone in this city are not at greater risk than others. The six items on which the population was standardized were therefore sex, age, marital status, social class, overcrowding and unemployment.

\section{Collection of Data}

The parasuicide group consisted of patients admitted to the RPTC following an overdose of drugs or an attempt at self injury. The work of the RPTC has been described more fully elsewhere (Matthew, Proudfoot, Brown and Aitken, 1969). For the present study we selected persons who were admitted from an Edinburgh address between 1 January and 31 December, 1968; those admitted 
more than once within this period were included for their first admission only. As the information is collected routinely in a clinical interview with the patient, items are sometimes missing, either because they have not been asked or because they are not obtainable. Any patient whose address, sex, age or marital status was unknown was automatically excluded from the study. Three per cent. were excluded in this way: the number of patien ${ }^{\star} \subseteq$ remaining for study was 642 .

Information on the general population was obtained from the Sample Census of 1966. So that we could make a sufficiently detailed analysis the General Register Office kindly provided data in the form of specially prepared abstracts from the census punched cards. These abstract cards, covering a $10 \%$ sample of the city's population, effectively recorded only the six variables in which we were interested plus a coding for the city ward (the ward populations range from about 10,000 to about 36,000 ). They thus gave no data which might have identified a particular individual. We subsequently computed our own analysis from these cards. Table I shows the categories used for each of the six variables in the analysis.

Sex, age, city ward and social class (General Register Office, 1966) were classified in directly comparable ways in both groups. Because of the small numbers of patients from classes I and II these were grouped in all analyses. Men and single and divorced women were classified according to their own occupation; married women and widows according to their husbands' occupations; and children or students by their fathers' occupations. The patient group had an additional civil state category-'cohabiting'. As the legal marital status of these people was unknown they were grouped with the married in this study.

In order to have comparable data on the attempted suicides and the general population for overcrowding, people living at a density of 1.5 persons per room and over were classified as overcrowded in both groups. ${ }^{1}$ Persons in lodgings, hostels or institutions were classified as not overcrowded in both groups.

As employment is less easy to define for women, this variable was used only for men. 'Unemployed' was interpreted as not in employment on census day or (for the patients) without a job at the time of admission. Those who were retired, students or 'others economically inactive' were classed as 'not applicable'.

\section{Method of ANALYsis}

The standardization procedure was as follows:

1. The parasuicides for the whole city were tabulated by the six variables subdivided as described in Table I.

\footnotetext{
1 The more usual classification is to term those living at over 1.5 1The more usual classification is to term those living at over 1.5
persons per room as overcrowded. In practice this means we have persons per room as overcrowded. In practice this means we have whereas many workers have not. Our definition is the same for both the patient sample and population.
}

TABLE I

THE SUBDIVISION OF VARIABLES

\begin{tabular}{|c|c|c|}
\hline II & $\begin{array}{l}\text { Sex: } \\
\text { Age (years): }\end{array}$ & $\begin{array}{ll}\text { Male, Female } & \\
\text { Less than 15 } & 35-44 \\
15-19 & 45-54 \\
20-24 & 55-64 \\
25-34 & 65 \text { and over }\end{array}$ \\
\hline III & $\begin{array}{l}\text { Marital status: } \\
\text { Social class: }\end{array}$ & $\begin{array}{l}25-34 \\
\text { Single, Married, Widowed, Divorced } \\
\text { I and II; III; IV; V; Not known or not }\end{array}$ \\
\hline V & Overcrowding: & $\begin{array}{l}\text { Less than } 1.5 \text { persons per room; } \\
1.5 \text { persons per room and over; } \\
\text { Not known or not applicable }\end{array}$ \\
\hline VI & $\begin{array}{l}\text { Employment } \\
\text { (males only): }\end{array}$ & $\begin{array}{l}\text { Employed, Unemployed, Not known or not } \\
\text { applicable }\end{array}$ \\
\hline
\end{tabular}

This tabulation thus comprises 2,880 cells. (An example of a single cell would be: males aged 25-34, single, social class IV, overcrowded and employed).

2. A similar tabulation was made for the general population of Edinburgh city and the parasuicide rate was calculated for each of the 2,880 cells.

3. The general population of each city ward was then tabulated in the same way.

4. The expected number of parasuicides in a given ward was calculated by multiplying the number of persons in each of the cells by the city rate for the corresponding cell and totalling the results for that ward.

Two difficulties arose in the application of this procedure. Firstly, about one-third of all parasuicides had information missing on one or more of the variables, social class, overcrowding and unemployment. If only one of the three items was missing we calculated the expected numbers on the basis of the known information (i.e., instead of standardizing on 6 items for men and 5 for women, we used the available 5 for men and 4 for women). This was done for 170 patients. The expected numbers for the remaining 55 patients on whom more than one item was missing were calculated by standardizing for age, sex and marital status only.

Secondly, such detailed tabulations produce small numbers in the cells. In the tabulation of the population of Edinburgh city 14 cells were empty but the corresponding cell in the tabulation of patients contained a person. No information is therefore available about the rate for these cells. To allow for this the number of patients from whom no cell expectation was calculable $(n=14)$ was divided by the number of wards $(n=23)$ and the result $(0 \cdot 61)$ was added to the expected number for each city ward.

A goodness of fit test $\left(\chi^{2}\right)$ was applied first to the observed and expected numbers based only on those patients for whom records were complete. The observed and expected numbers were then supplemented by those based on incomplete records and the test was repeated.

In addition, the ratios of the numbers observed to those expected after standardization (standard 
morbidity ratios or SMRs) for each ward were calculated. For comparison, crude morbidity ratioscalculated by multiplying the parasuicide rate for the city as a whole by the population in each ward-and SMRs derived after standardizing on age and sex only, are also given.

\section{RESULTS}

The goodness of fit test calculated for the numbers observed and those expected on the 417 patients on whom information was available on all items produces $\chi_{22}^{2}=45 \cdot 90$, significant at the $1 \%$ level. The goodness of fit test calculated on the 642 persons comprising the total patient sample is also highly significant $\left(\chi_{22}^{2}=57.78, \mathrm{P}>0.001\right)$. A comparison of the numbers observed with those expected is given in Table II. The null hypothesis that simultaneous

TABLE II

COMPARISON OF OBSERVED NUMBERS WITH NUMBERS EXPECTED AFTER STANDARDIZATION ON 6 VARIABLES (ALL PATIENTS)

\begin{tabular}{c|c|c}
\hline Electoral Ward & Observed & Expected \\
\hline 1 & 49 & $31 \cdot 62$ \\
2 & 13 & $18 \cdot 44$ \\
3 & 27 & $17 \cdot 32$ \\
4 & 24 & $26 \cdot 74$ \\
5 & 34 & $50 \cdot 57$ \\
6 & 25 & $18 \cdot 09$ \\
7 & 23 & $16 \cdot 78$ \\
8 & 27 & $29 \cdot 78$ \\
9 & 30 & $27 \cdot 89$ \\
10 & 31 & $29 \cdot 87$ \\
11 & 9 & $23 \cdot 56$ \\
12 & 27 & $27 \cdot 10$ \\
13 & 54 & $49 \cdot 49$ \\
14 & 23 & $33 \cdot 70$ \\
15 & 14 & $16 \cdot 56$ \\
16 & 22 & 22.95 \\
17 & 35 & $25 \cdot 54$ \\
18 & 14 & $20 \cdot 43$ \\
19 & 27 & $32 \cdot 44$ \\
20 & 24 & $27 \cdot 20$ \\
21 & 25 & $32 \cdot 65$ \\
22 & 29 & $37 \cdot 09$ \\
23 & 56 & $642 \cdot 01$ \\
\hline Total & 642 & \\
\hline
\end{tabular}

$\chi^{2}=57 \cdot 78$, d.f. $=22, P<0.001$

standardization of the populations on sex, age, civil state, social class, overcrowding and unemployment would eliminate the difference in parasuicide rates between wards is therefore not supported. Despite standardization, considerable variation between areas remained, as illustrated in the Figure.

Examination of the morbidity ratios enables us to make certain other observations (Table III). Despite standardization on all six variables, certain wards have ratios markedly different from 100; in particular, the values for wards 1,3 and 23 were more than 150 whereas ward 11 had a SMR of below 40 .

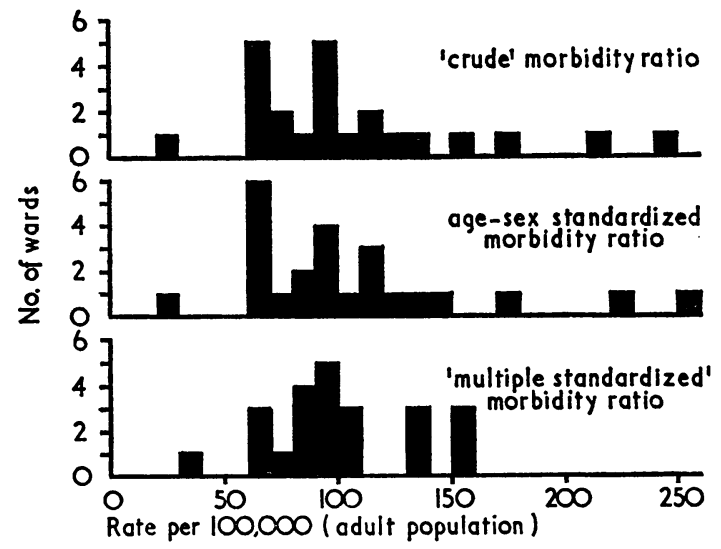

FIGURE-Effects of standardization on 'crude' morbidity ratio.

TABLE III

COMPARISON OF THREE MORBIDITY RATIOS (CRUDE, AGE-SEX STANDARDIZED AND MULTIPLE STANDARDIZED)

\begin{tabular}{|c|c|c|c|}
\hline \multirow[b]{2}{*}{$\begin{array}{l}\text { City } \\
\text { Ward }\end{array}$} & \multicolumn{3}{|c|}{ Morbidity Ratios } \\
\hline & Crude & $\begin{array}{c}\text { Age-sex } \\
\text { Standardized }\end{array}$ & $\begin{array}{l}\text { Standardized } \\
\text { on six Variables }\end{array}$ \\
\hline $\begin{array}{r}1 \\
2 \\
3 \\
4 \\
5 \\
6 \\
7 \\
8 \\
9 \\
10 \\
11 \\
12 \\
13 \\
14 \\
15 \\
16 \\
17 \\
18 \\
19 \\
20 \\
21 \\
22 \\
23\end{array}$ & $\begin{array}{r}248 \\
88 \\
155 \\
79 \\
66 \\
109 \\
112 \\
65 \\
97 \\
124 \\
26 \\
67 \\
130 \\
68 \\
96 \\
98 \\
178 \\
62 \\
114 \\
98 \\
91 \\
79 \\
217\end{array}$ & $\begin{array}{r}258 \\
94 \\
147 \\
78 \\
64 \\
115 \\
112 \\
64 \\
96 \\
120 \\
25 \\
69 \\
132 \\
66 \\
90 \\
95 \\
174 \\
64 \\
112 \\
100 \\
93 \\
83 \\
221\end{array}$ & $\begin{array}{r}155 \\
70 \\
156 \\
90 \\
67 \\
138 \\
137 \\
91 \\
108 \\
104 \\
38 \\
100 \\
109 \\
68 \\
84 \\
96 \\
137 \\
68 \\
83 \\
92 \\
92 \\
89 \\
151\end{array}$ \\
\hline
\end{tabular}

To make some (though approximate) estimate of how much of the variation had been accounted for by the standardization exercise, the variance was calculated for each of the three sets of morbidity ratios (Table IV). Standardization for age and sex alone does not reduce the variance at all. Simultaneous standardization on six variables reduces the variance by nearly two-thirds.

Consideration was given to further analysis which would demonstrate the importance of each variable individually. This was not pursued, partly because the variables are known to interact with each other and it would not have been practicable to test for all possible combinations. Moreover, the variance 
TABLE IV

MEANS AND VARIANCES OF THE MORBIDITY RATIOS

\begin{tabular}{l|c|c}
\hline \multicolumn{1}{c|}{ Morbidity Ratio } & Mean & Variance \\
\hline Crude & $\begin{array}{c}107 \cdot 3 \\
\text { Age-sex standardized }\end{array}$ & $\begin{array}{r}2,628.6 \\
\text { Multiple standardized }\end{array}$ \\
\hline
\end{tabular}

around the SMR can only be considered an approximate measure.

Population migration was also considered as a possible explanation of differences in area rates. Figures for migration into and within the city are published by the General Register Office and from these data we derived for each city ward three indices of population movement: firstly, the percentage of the adult population who had moved in the precensus year from one part of the city to another; secondly, the percentage who had moved into the city from outside; and, thirdly, a combination of the first two measures. The indices were then correlated with the three morbidity ratios previously described (crude, age-sex standardized and multiple standardized). None of the rank-order correlation co-efficients even approached the level required for statistical significance. Thus, although there are other data to suggest an association between parasuicide and migration for the city as a whole, population movement is not an important source of variation in rates between city wards.

The conclusion is therefore drawn that the factors examined are not sufficient to account for the discrepancy in area rates though they go some way towards identifying the source of variation between wards.

\section{Discussion}

The principles which underline the method used in this study are well established. The use of population sub-groups defined by multiple variables applied simultaneously have clear advantages over any standardization procedure in which the effects of the variables are considered successively, since no inferences have to be made about the correlations between the variables. The large number of cells in the tabulations means that the numbers within each are sometimes very small and hence sensitive to random error, but such errors are not systematic and do not affect the interpretation of the final result. Indeed the main limitation on the number of cells that can be employed is that of obtaining enough data on the population under study.

From Table III it can be seen that the use of the usual age-sex standardization to produce a Standardized Morbidity Ratio leads to little change from the pattern obtained by the crude morbidity ratios (derived only from the size of the population in the city wards). It might be inferred from this that the age-sex structure of the various wards is fairly homogeneous, so that adjustment for population structure produces little effect. The Census confirms that there is indeed little obvious variation between the wards of the city in terms of the proportions in the usual age-sex categories. However, the introduction of further variables into the standardization procedure to produce 'multiple-standardized morbidity ratios' for each ward results in substantial changes; the highest SMR (ward 1) falls from 258 to 155 while the lowest (ward 11) increases from 25 to 38 . The total variance falls by about two-thirds as previously noted.

It is important to appreciate just what has and has not been achieved by the procedure adopted. It is now possible to say that about two-thirds of the variance in the ward morbidity ratios can be 'accounted for' in the statistical sense that the source of a proportion to total variance has been indentified. It is not possible to say that the variables used in the standardization procedure 'cause' parasuicide to a degree reflected in the reduction of inter-ward variation. The variables studied can be only indirectly related to 'causal' processes, the precise relationship remaining obscure. For causation to be established a causative theory needs to be set up and verified and that has not been attempted here.

Perhaps the main implication of the results is that residence in different city wards remains an interesting source of difference in the rates of parasuicidal behaviour. The addition of further variables of the kind already considered, which can be readily ascribed to individual members of the population in a census-type survey, might eliminate the remaining difference in the ward rates. Alternatively, attitudes, beliefs and patterns of interaction between individuals which cannot be conveniently described as individual characteristics, may be more fruitfully investigated. The theoretical problems which emerge at this point we hope to explore more fully elsewhere as a prelude to further studies.

\section{SUMMARY}

1. An explanation of the known variation in parasuicide rates between different wards of the city of Edinburgh was attempted in terms of the social and demographic characteristics of the general population of the ward.

2. Information was obtained on 642 parasuicides admitted to the Regional Poisoning Treatment Centre in the course of 1968 and on the general 
population of Edinburgh as recorded in the Sample Census (1966).

3. The observed number of parasuicides from each city ward was compared with the number expected after standardization of the population on six variables-sex, age, civil state, social class, overcrowding and unemployment. Three morbidity ratios (crude, age-sex standardized and multiple standardized) were calculated.

4. After standardization on six variables a statistically significant difference in parasuicide rates remained but the variance of the morbidity ratios was reduced by about two-thirds.

We should like to express our appreciation to Dr. Henry Matthew, physician-in-charge of the Regional Poisoning Treatment Centre, for permitting access to patient records, and to the medical and psychiatric staff of the Centre for their co-operation. We are greatly indebted to the Registrar General for Scotland and to members of his staff for permission to make use of unpublished Census material and for their help in preparing the Census cards. Thanks are also due to the Edinburgh Regional Computing Centre for advice on programming techniques and to Professor G. M. Carstairs and colleagues of this unit for their helpful comments.

\section{REFERENCES}

Aitken, R. C. B., Buglass, D., and Kreitman, N. (1969). The changing pattern of attempted suicide in Edinburgh, 1962-67. Brit. J. prev. soc. Med., 23, 111. Kessel, N. (1965). Self-poisoning: The Milroy Lectures for 1965. Brit. med. J., 2, 1265, 1336.

Matthew, H., Proudfoot, A. T., Brown, S. S., and AITKEN, R. C. B. (1969). Acute poisoning: organization and work-load of a treatment centre. Brit. med. J., 3, 489.

McCulloch, J. W., Philip, A. E., and Carstairs, G. M. (1967). The ecology of suicidal behaviour. Brit. $J$. Psychiat., 113, 313.

Philip, A. E., and McCulloch, J. W. (1966). Use of social indices in psychiatric epidemiology. Brit. $J$. prev. soc. Med., 20, 122.

General Register OfFice (1966). Classification of Occupations, 1966. H.M.S.O., London. 